\title{
Are Brazilian dentists and dental students using the ICCC recommendations for caries management?
}

\author{
Guilherme Coelho SALES(a) \\ Marta Gomes MARQUES(a) \\ Dayane Rezende RUBIN(a) \\ Daniele Nóbrega NARDONI(a) \\ Soraya Coelho LEAL(a) (iD) \\ Leandro Augusto HILGERT(a) \\ Nailê DAME-TEIXEIRA ${ }^{(a)}$ \\ (a) Universidade de Brasília - UnB. School of \\ Heath Sciences. Department of Dentistry. \\ Brasilia. DF. Brazil
}

Declaration of Interests: The authors certify that they have no commercial or associative interest that represents a conflict of interest in connection with the manuscript.

\section{Corresponding Author:}

Marta Gomes Marques

E-mail:martagmqs@gmail.com

htpp://doi.org/10.1590/1807-3107bor-2020.vol34.0062

Submitted: February 3, 2020

Accepted for publication: April 7, 2020

Last revision: May 6, 2020

\begin{abstract}
The aim of this study was to evaluate whether dentists and dental undergraduate students know the terminology of the International Caries Consensus Collaboration (ICCC), and make their restorative treatment decisions regarding carious tissue removal accordingly. Data collection was performed using an electronic questionnaire, considering: a) profile of the respondent; b) analysis of four clinical cases with respect to possible management strategies; and c) questions on cariology field terminology. Sample size consisted of 175 dentists and 66 last semester dental students. Statistical analyses were performed comparing profile, type of institution and dental specialty of the participants. Results showed students were less conservative and agreed less with the ICCC than dentists, and private schools, less than public institutions. Private institutions were $12 \%(95 \% \mathrm{CI}=0.833-0.949$; $\mathrm{p}=0.000$ ) more likely to be less updated with the ICCC recommendations than public institutions, and dentists were $20 \%$ more likely to agree with them than students $(95 \% \mathrm{CI}=1.118-1.302 ; \mathrm{p}=0.000)$. Dentists were $66 \%$ more likely to be conservative than students $(95 \% \mathrm{CI}=0.203-0.554$; $\mathrm{p}=0.000$ ); dentists and students who graduated or were graduating from public universities were twice as likely to be conservative as those from private universities $(95 \% \mathrm{CI}=1.336-3.333 ; \mathrm{p}=0.001)$. In conclusion, students in the last semester are less conservative than dentists, and respondents who graduated or were graduating from public dental schools were more aligned with the current concepts of the ICCC. Several answers were not aligned with ICCC directives, thus showing that management of deep carious lesions still causes restorative therapeutic insecurity.
\end{abstract}

Keywords: Dental Caries; Preventive Dentistry; Dentistry, Operative; Evidence-Based Dentistry.

\section{Introduction}

Complete caries removal with cavity preparation extending to sound dental tissue was advocated by Greene Vardiman Black in 1893, and was considered the gold standard treatment of decayed teeth for many years. ${ }^{1.2}$ With the advances made in understanding the etiopathogenesis of the caries process, and in developing adhesive materials, more conservative approaches were proposed. This approach is one of the pillars of the 
Minimum Intervention Dentistry (MID) philosophy, MID aims to maintain healthy functional teeth for life, ${ }^{3}$ by reducing postoperative complications and preserving sound dental structure. ${ }^{4}$

It is known that a divergence exists in dental restorative terminology, diagnosis and decisionmaking processes in clinical practice. This leads to an inconsistency in carious lesion management. In an effort to standardize therapeutic protocol and diagnostic procedures, the International Caries Consensus Collaboration (ICCC) brought together 21 experts in cariology from 12 different countries. The expert consensus aimed to synthesize well-grounded evidence collected from the literature into clear, unambiguous recommendations. ${ }^{4.5}$ The ICCC presented clinical recommendations for carious tissue removal and cavitated carious lesion management based on the texture of demineralized dentine and lesion depth. However, there is no way of estimating the impact of the recommendations on dentistry, in either clinical or academic universes.

We can hypothesize that undergraduate students are still being trained in concepts and principles based merely on invasive intervention, rather those of seeking treatment and restorative decision-making processes based on behaviorally controlling the causative factors of dental caries. In terms of dental professionals, there is conflicting evidence about how well they follow evidence-based recommendations for their restorative care planning ${ }^{6.7}$ Recently, a web-based questionnaire survey was conducted in Scandinavia to determine the trend of using MID. ${ }^{8}$ The study has shown that dentists from countries with a high socioeconomic level still tend to intervene operatively at a very early stage of caries, although there are variations among the countries evaluated. However, there is no information on this trend in developing countries, such as Brazil. Moreover, we are aware that there is a gap between gathering evidence and applying it in the professional's daily practice. ${ }^{9}$ It is unknown whether this also affects academia, where new dentists are being trained. Therefore, our aim was to evaluate whether dentists and dental undergraduate students know dental terminology and base their restorative treatment decisions regarding carious tissue removal on the recommendations of the ICCC of 2015.

\section{Methodology}

This study was approved by the Research Ethics Committee of the School of Health Sciences of the University of Brasilia (approval number 01540818.9.0000.0030). All participants signed an informed consent form electronically.

\section{Sampling procedure}

The research was carried out in the Federal District (DF) of Brazil. The estimated population was 2.9 million inhabitants in 2018, according to official data (IBGE, 2018), and seven dental schools were operating in the DF when the study was carried out. The study included both undergraduate students and dentists working in the dental field. Exclusion criteria consisted of students not in the last semester of their dental course at the time of the data collection, or dentists who were not registered at the Regional Board of Dentistry (CRO-DF).

Sample size was calculated based on the total target population for students and dentists (openepi.com/ SampleSize). The total number of dentists in the DF ( $n=7.382$ ) and a precision level of $\pm 5 \%$ for the $95 \%$ confidence interval (CI) were used to calculate the number of dentists to be included. A non-response rate of $30 \%$ was added for a final sample size estimated at $\mathrm{n}=230$ dentists. As for the students, the total target population comprised 276 students (the number of students in the last semester of the dentistry course from August to December 2018 was: Universidade Paulista $n=91$; Centro Universitário UNIEURO $\mathrm{n}=80$; Universidade Católica de Brasília $\mathrm{n}=50$; Universidade de Brasília $n=25$; FACIPLAC $n=30$ ). A precision level of $\pm 5 \%$ for the $95 \%$ CI was another parameter used in this calculation, for a sample size of $n=93$. Considering a non-response rate of $30 \%$, all students were invited to participate.

\section{The electronic questionnaire}

An electronic questionnaire (GoogleForms ${ }^{\odot}$ ) was developed specifically for this study. It was tested previously in a pilot study that comprised 10 respondents: five undergraduate students and five dentists, all of whom were asked about the clarity and structure of the questionnaire. Their comments 
and suggestions were used to adjust the instrument. The internet link to the questionnaire was sent to the participants via email and social media (WhatsApp ${ }^{\odot}$. All invitations were sent twice to dental professionals from an email list of a referenced radiology center in the DF. The deans of the dental schools kindly sent the questionnaire to all last semester students. Data collection was performed from November 2018 to April 2019.

The questionnaire was divided into three parts:

a. Respondents' characteristics: sociodemographic variables (age, gender), dental education background (type of institution of graduation, number of years since graduation, academic degree and dental specialty), and self-declared degree of updatedness in cariology. Answer options included: totally outdated, partially outdated, neutral, partially updated and fully updated, based on how often the respondent felt the need to get updated, and/or the urge to search for updated information in the cariology field.

b. Clinical cases: The questionnaire contained four clinical cases, and required that respondents decide what their tooth restoration of choice was. The case descriptions and the different options of responses are presented in Table 2 below.

c. Agreement to ICCC sentences: sentences based on ICCC recommendations ${ }^{5}$ in Brazilian Portuguese were provided. The options available to the respondents in each sentence were: totally disagree, partially disagree, do not know, totally agree and partially agree. The sentences are described below:

Sentence 1 - "Currently, carious tissue management of permanent teeth is based on selective removal to avoid pulpal exposure, and the parameters for removal are the clinical criteria of hardness and depth. Residual contamination below the restoration does not compromise the restorative treatment."

Sentence 2 - "In deep lesions of vital pulp teeth, preservation of pulp health should be prioritized, thereby allowing soft/leathery dentin to be maintained over the pulp."

Sentence 3 - "Selective removal up to firm dentin is the treatment of choice for both shallow and medium cavitated carious lesions."
Sentence 4 - "Nonselective removal to hard dentin, formerly known as complete excavation or complete removal of carious tissue, is no longer recommended as an approach for carious lesion management."

\section{Data analysis}

The outcomes were represented by the responses to clinical cases, and by the agreement with ICCC sentences, both analyzed by two different methods: a) categorical variables, as a proportion of answers to each option; and b) the sum of scores for each answer ("Conservative" and "ICCC Agreement" variables). The variable we called "Conservative" aimed to evaluate the degree of conservative responses, based on a scale from minor to greater invasiveness applied in each clinical case. The scores corresponding to the responses to the four clinical cases were summed up, considering that lower values corresponded to more conservative decisions. and higher values, to less conservative ones. The variable we called "ICCC Agreement" was measured using a Likert scale, in which the responses were summed up to obtain a count variable. Lower values represented less agreement with the ICCC, and higher values represented more agreement.

The sociodemographic explanatory variables, dental education background and self-declared level of updatedness in cariology were computed, and the findings were analyzed descriptively. The chi-square test was used to investigate the association between categorical outcomes and explanatory variables (except for the individual's age and training time). The dentist's specialty was categorized as follows: "pediatric dentistry OR pediatric dentistry + other specialties," "operative dentistry or operative dentistry + other," and "endodontics OR endodontics + other." Analysis of the type of institution of graduation, whether private or public, included both students and dentists.

The data distribution of the "Conservative" and "ICCC Agreement" variables was checked by the Kolmogorov-Smirnov test; Poisson distribution for ICCC agreement and linear distribution for Conservative were identified. The Mann-Whitney test was used to compare mean values of the "Conservative" and "ICCC Agreement" outcomes between students 
and professionals, and between the types of institution, whether public or private. Unadjusted Poisson and linear regressions were then performed to confirm the hypothesis of association between outcomes and type of institution, and between dentists and students. Analyses were performed using SPSS software version 25.0 for Mac (SPSS Inc., Chicago, USA). The significance level considered was $\mathrm{p}<0.05$.

\section{Results}

The response rate for the students was $28.7 \%$. As for the professionals, an estimate could not be made, since we did not know the number of dentists who actually received the email. Since the previously predicted number of students was not attained, the power of the study had to be calculated. The values obtained were 99.81\% for the "ICCC Agreement" variable, whereas the power for the "Conservative" variable was $97.15 \%$. Both calculations considered means and standard deviations, as well as a $95 \% \mathrm{CI}$ for a two-tailed test (openepi.com).

Table 1 describes the sampling characteristics of the study. The mean age of the respondents was $24.7 \pm 4.0$ years and $36.4 \pm 9.7$ years for students and dentists, respectively. The average time since graduation of dentists was $12.97 \pm 9.79$ years. The female gender was predominant in the sample (about 73\%). No significant association was found between the gender variable and the clinical case responses (chi-square; $p>0.05$ ). The type of institution of graduation of the respondents was similar. Regarding the self-declared degree of updatedness in cariology, most respondents were self-declared as partially updated $(60 \%)$, followed by fully updated (18.6\%), neutral (5.8\%) and partially outdated (6.2\%). There was no significant association between this variable and the clinical case responses (chi-square. $\mathrm{p}>0.05$ ).

In regard to the dentists, the most common academic degree was specialization (53.1\%), followed by master's degree (21.1\%), and just university graduation (18.2\%). Moreover, $7.4 \%$ of the respondents held a $\mathrm{PhD}$ degree. No significant association was found between the academic degree and the clinical case responses (chi-square; $\mathrm{p}>0.05$ ). Regarding the specialty, $18.2 \%$ of the respondents had no specialization (18.2\%),
$17.7 \%$ were endodontists, $14.8 \%$ were specialists in pediatric dentistry and $14.8 \%$, in operative dentistry. The chi-square test showed no association between this variable and the clinical case responses. The professionals also answered in regard to their area of employment. Dentists self-employed in private practice were the majority $(44 \%)$, followed by the academic area $(24 \%)$, public service $(22 \%)$, and a combination of public service and private practice $(9 \%)$. The association of this variable with clinical case responses was tested, with no statistical significance for the four clinical cases (chi-square, $p>0.05$ ).

Table 2 shows the responses to the clinical case questionnaire. The most commonly chosen answer for clinical case \#1 was "restoration with removal of soft carious tissue, leaving hard dentin peripherally" (64.3\% of respondents). This was followed by "resinous sealing of the lesion without removal of carious tissue" (19.5\% of respondents). In clinical case \#2, there was a greater divergence of responses. Most of the participants (37.8\%) opted for stepwise excavation, and $28.6 \%$ of the respondents preferred selective removal up to soft dentin, followed by final restoration in the same session. As for clinical case \#3, the answer "no restorative intervention" was the most commonly chosen $(50.6 \%)$, followed by the answer favoring repair (32.4\%). In clinical case \#4, the polishing response was the most commonly chosen $(68.9 \%)$ followed by the non-intervention answer (24.1\%). Associations were made between clinical cases and variables (dentist vs. student and public vs. private type of institution) (chi-square). Clinical cases \#1 ( $p=0.7$ and $p=0.42$, dentist vs. student and public vs. private type of institution, respectively) and $\# 4$ ( $p=0.08$ and $p=0.19$, respectively) showed no differences in treatment decision-making options (for shallow lesions and restoration changes, respectively). However, analysis showed statistically significant differences for clinical cases \#2 ( $p=0.001$ and $p=0.002$, dentist vs. student and public vs. private type of institution, respectively) and \#3 ( $p=0.000$ and $p=0.009$, respectively), both presenting deep lesions in dentin.

Regarding the sentences about current concepts in cariology based on the ICCC, we found that most of the participants agreed with them, totally and 
Table 1. Sampling characteristics of the respondents.

\begin{tabular}{|c|c|c|c|}
\hline \multirow{2}{*}{ Variable } & Dentists & Students & \multirow{2}{*}{ Total } \\
\hline & $(\%)$ & $(\%)$ & \\
\hline \multicolumn{4}{|l|}{ Gender } \\
\hline Female & $128(73.1)$ & $47(71.2)$ & 175 \\
\hline Male & $47(26.8)$ & $19(28.7)$ & 66 \\
\hline \multicolumn{4}{|l|}{ Type of institution } \\
\hline Private & $84(62.6)$ & $50(37.3)$ & 134 \\
\hline Public & $91(85)$ & $16(14.9)$ & 107 \\
\hline \multicolumn{4}{|c|}{ Degree of updatedness in cariology (self-declared) } \\
\hline Totally outdated & $2(66.6)$ & $1(33.3)$ & 3 \\
\hline Partially outdated & $13(86.6)$ & $2(13.3)$ & 15 \\
\hline Neutral & $9(64.2)$ & $5(35.7)$ & 14 \\
\hline Partially updated & $106(73.1)$ & $39(26.8)$ & 145 \\
\hline Fully updated & $45(70.3)$ & $19(29.6)$ & 64 \\
\hline \multicolumn{4}{|l|}{ Higher education } \\
\hline Graduation & $32(18.2)$ & NA & 32 \\
\hline Specialization & $93(53.1)$ & NA & 93 \\
\hline Master's degree & $37(21.1)$ & NA & 37 \\
\hline Doctor's degree & $13(7.4)$ & NA & 13 \\
\hline \multicolumn{4}{|l|}{ Dental specialty } \\
\hline No specialization & $32(18.2)$ & NA & 32 \\
\hline Pediatric dentistry & $26(14.8)$ & NA & 26 \\
\hline Operative Dentistry & $26(14.8)$ & NA & 26 \\
\hline Endodontics & $31(17.7)$ & NA & 31 \\
\hline Prosthesis & $17(9.7)$ & NA & 17 \\
\hline Other & $43(24)$ & NA & 43 \\
\hline \multicolumn{4}{|l|}{ Area of employment } \\
\hline Academic & $42(24)$ & NA & 42 \\
\hline Private practice & $77(44)$ & NA & 77 \\
\hline Public service & $39(22.2)$ & NA & 39 \\
\hline Public service and private practice & $16(9.1)$ & NA & 16 \\
\hline
\end{tabular}

NA: Not applicable.

partially (sentence 1 - 70.6\%; sentence 2 - 68.3\%; sentence 3 - 64.7\%; and sentence 4 - 82.5\%) (Table 3).

Table 4 shows the means of the "Conservative" responses to the clinical cases and the "ICCC Agreement" for students vs. dental professionals, and for type of institution (public vs. private). The Mann-Whitney test found statistically significant differences, specifically, a higher mean for dentists than students, and more updated respondents from public than private dental schools.

Poisson regression showed a $22 \%$ (95\% CI $=0.833-0.949$; $\mathrm{p}=0.000)$ greater chance of students/dentists from private institutions being less updated than those from public institutions, and dentists were $20 \%$ more likely to agree with the ICCC than students $(95 \% \mathrm{CI}=1.118-1.302 ; \mathrm{p}=0.000)$. Linear regression models showed that dentists were $66 \%$ more likely to be conservative than students $(95 \% \mathrm{CI}=0.203-0.554$; $\mathrm{p}=0.000)$, and dentists or students attending undergraduate courses in public institutions were twice as likely to be conservative as those from private institutions $(95 \% \mathrm{CI}==1.336-3.333 ; \mathrm{p}=0.001)$ (Table 4$)$. It is important to note that the "type of institution" variable considered all those who had graduated (dentists) or were undergraduates (in the last semester) whether from public or private universities. 
Table 2. Description of the clinical cases and answers.

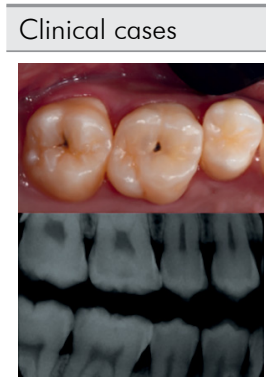

Clinical case \# 1 - "Tooth 16 with

occlusal caries lesion, as shown in the image/X-ray. Tooth presents complete rhizogenesis; symptoms and clinical signs of active cavity lesion in the middle third of dentin are indicative of pulp vitality (positive response to the cold sensitivity test, absence of pain to percussion, absence of spontaneous pain or continuous provoked pain). The radiographic image shows no involvement of the pulp. What would you do in this case?"

Options of answer

1. No restorative intervention.

2. Resinous sealing of the lesion without removal of carious tissue.

3. Restore by removing soft carious tissue. leaving hard dentin peripherally.

4. Annual clinical and radiographic follow-up.

5. Remove carious tissue from the surrounding walls and restore with composite resin.

6. Glass ionomer (sealing or restoration). Total

Clinical case \#2 - "Young patient, tooth 27 with complete rhizogenesis; symptoms and clinical signs are indicative of pulp vitality (positive response to the test of sensitivity to cold, absence of pain to percussion, absence of spontaneous pain or continuous provoked pain). The radiographic image shows no involvement of the pulp. The case presents clinically and radiographically as shown in the images below. What would you do in this case?"

1. Stepwise excavation leaving a layer of soft dentin over the pulp, covered with calcium hydroxide cement and glass ionomer cement. Remove the rest of the soft tissue after 30 to 90 days. and make the final restoration.

2. Leave some soft tissue on the pulp, in order to avoid pulpal exposure, and perform final restoration in the same session.

3. Remove all the soft tissue following the clinical criteria of hardness. If there is pulp exposure, perform pulp curettage and protection with calcium hydroxide $\mathrm{PA}+$ calcium hydroxide cement and glass ionomer cement.

4. Remove all soft tissue following the clinical criteria of hardness, and perform pulpotomy if there is pulp exposure.

5. Perform endodontic treatment (pulpectomy).

6. Stepwise removal, leaving a layer of soft dentin over the pulp, covered with calcium hydroxide cement and glass ionomer cement. Make a final restoration after 30 to 90 days.

7. Remove all soft tissue; disinfect with $2 \%$ chlorhexidine; apply glass ionomer cement; wait to assure no pain symptom; perform final restoration.

\begin{tabular}{ccc} 
Dentists (\%) & Students (\%) & Total \\
\hline $20(66.6)$ & $10(33.3)$ & 30 \\
$36(76.6)$ & $11(23.4)$ & 47 \\
$111(71.6)$ & $44(28.3)$ & 155
\end{tabular}

$\begin{array}{ccc}2(100) & 0(0) & 2 \\ 3(75) & 1(25) & 4 \\ 3(100) & 0(0) & 3 \\ 175 & 66 & 241\end{array}$

66(72.5) 25(27.5)

8. Remove all soft tissue + indirect pulp capping Total

1. No restorative intervention.

$1(50) \quad 1(50) \quad 2$

6(66.6) $\quad 3(33.3) \quad 9$

$1(100) \quad 0(0) \quad 1$
complete rhizogenesis; signs and symptoms indicative of pulp vitality; the radiographic image shows no involvement of the pulp. Tooth presents a class I restoration with composite resin performed 10 years ago, clinically acceptable; no sign of adjacent caries. The case presents radiographically as shown in the images below. What would you do in this case?"

2. Repair (finish and polish) the restoration.

3. Change the restoration for another direct restoration.

4. Restore with a fixed prosthesis.

5. Conduct radiographic follow-up in 6 to 8 months.

\begin{tabular}{lccc} 
Total & 175 & 66 & 241 \\
\hline 1. No restorative intervention. & $48(82.7)$ & $10(17.2)$ & 58 \\
2. Finish and polish restoration. & $117(70.5)$ & $49(29.5)$ & 166 \\
3. Change the restoration for composite resin. & $10(58.8)$ & $7(41.2)$ & 17 \\
\hline Total & 175 & 66 & 241
\end{tabular}

Clinical case \#4 - "Would you replace the restoration below? Patient did not complain of the restoration and the radiographic image is not compatible with adjacent carious lesion."

adjacent carious lesion."

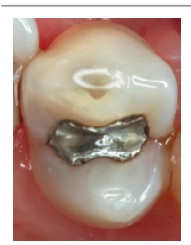

Image from clinical case \#3 from Alves et al. ${ }^{19}$ 
Table 3. ICCC sentences and level of agreement (1 - totally disagree, 2 - partially disagree, 3 - do not know, 4 - partially agree, 5 - totally agree).

\begin{tabular}{|c|c|c|}
\hline ICCC sentences & Level of agreement & n (\%) \\
\hline \multirow{5}{*}{$\begin{array}{l}\text { "Currently, carious tissue management of permanent teeth is based on selective removal } \\
\text { to avoid pulpal exposure, and the parameters for removal are the clinical criteria of } \\
\text { hardness and depth. Residual contamination below the restoration does not compromise } \\
\text { the restorative treatment." }\end{array}$} & 1 & $84(34.9)$ \\
\hline & 2 & $86(35.7)$ \\
\hline & 3 & $7(2.8)$ \\
\hline & 4 & 37 (15.4) \\
\hline & 5 & 27 (1 1.2) \\
\hline \multirow{5}{*}{$\begin{array}{l}\text { "In deep lesions of vital pulp teeth, preservation of pulp health should be prioritized, } \\
\text { thereby allowing soft/leathery dentin to be maintained over the pulp." }\end{array}$} & 1 & $104(43.3)$ \\
\hline & 2 & $60(25)$ \\
\hline & 3 & $4(1.7)$ \\
\hline & 4 & $21(8.7)$ \\
\hline & 5 & $51(21.3)$ \\
\hline \multirow{5}{*}{$\begin{array}{l}\text { "Selective removal up to firm dentin is the treatment of choice for both shallow and } \\
\text { medium cavitated carious lesions." }\end{array}$} & 1 & $101(41.9)$ \\
\hline & 2 & 55 (22.8) \\
\hline & 3 & $6(2.5)$ \\
\hline & 4 & $34(14.1)$ \\
\hline & 5 & 45 (18.7) \\
\hline \multirow{5}{*}{$\begin{array}{l}\text { "Nonselective removal to hard dentin, formerly known as complete excavation or } \\
\text { complete removal of carious tissue, is no longer recommended as an approach for } \\
\text { carious lesion management." }\end{array}$} & 1 & $137(56.8)$ \\
\hline & 2 & $62(25.7)$ \\
\hline & 3 & $14(5.9)$ \\
\hline & 4 & $16(6.6)$ \\
\hline & 5 & $12(5)$ \\
\hline
\end{tabular}

Table 4. Mean values for dentists vs. students and type of institution regarding the "Conservative" and "ICCC Agreement" outcomes.

\begin{tabular}{|c|c|c|c|c|c|c|}
\hline Variable & $\mathrm{N}$ & Mean & Standard error & p-value (Mann-Whitney test) & $\operatorname{Exp}(B)(95 \% C l)$ & $p$-value \\
\hline \multicolumn{7}{|c|}{ ICCC Agreement* } \\
\hline Dentists & 175 & 15.78 & 3.28 & \multirow{2}{*}{0.000} & 1.207 (1.118-1.302) & \multirow[t]{2}{*}{0.000} \\
\hline Students & 66 & 13.08 & 3.89 & & 1 & \\
\hline Private & 134 & 14.25 & 3.99 & \multirow{2}{*}{0.001} & 1 & \multirow[t]{2}{*}{0.000} \\
\hline Public & 107 & 16.03 & 2.90 & & 0.889 (0.833-0.949) & \\
\hline \multicolumn{7}{|c|}{ Conservative** } \\
\hline Dentists & 175 & 7.85 & 1.68 & \multirow{2}{*}{0.000} & $0.336(0.203-0.554)$ & \multirow[t]{2}{*}{0.000} \\
\hline Students & 66 & 8.92 & 2.00 & & 1 & \\
\hline Private & 134 & 8.448 & 2.01 & \multirow{2}{*}{0.002} & $2.110(1.336-3.333)$ & \multirow[t]{2}{*}{0.001} \\
\hline Public & 107 & 7.701 & 1.51 & & 1 & \\
\hline
\end{tabular}

${ }^{*}$ Poisson regression model; ${ }^{* *}$ Linear regression model.

\section{Discussion}

This study aimed to evaluate how well dentists and dental students agreed with the ICCC recommended concepts, and assess attitudes and restorative decision-making processes regarding simulated clinical situations. An interesting finding is that dental students and dentists from private dental schools were less conservative in their restorative decision-making process than those from public dental schools (see below for the differences between public and private Brazilian higher education). The most striking result that emerged in this respect was the high divergence in restorative caries management regarding the clinical cases that presented deep carious lesions. This result demonstrates the uncertainty and lack of standardization in treatments for deep carious lesions. 
Clinical case \#1 illustrated the theoretical background behind the use of sealants without removal of carious tissue. The purpose was to evaluate how well dentists and dental students knew this treatment option. Interestingly, the majority of the participants $(64.3 \%)$ chose the option of selective caries tissue removal and conventional restorative protocol. Sealing the lesion without removing the carious tissue was the second most commonly chosen answer (19.5\%). Sealing this kind of lesions in vital and asymptomatic teeth, without prior removal of carious tissue, has been a topic of debate for decades. ${ }^{10}$ More recently, a randomized clinical trial assessed the efficacy of sealing occlusal carious lesions in permanent teeth ${ }^{11}$. The results demonstrated that sealing initial occlusal cavitated lesions might arrest caries progression, as seen over a period of 3-4 years of monitoring. Similarly, another clinical study ${ }^{12}$ aimed to assess the arrest of occlusal caries lesions after using resin sealants, and the radiographic response (regression, arrest and progression) of sealed lesions over the course of the follow-up (7 years). The results showed that using resin sealants, even in the case of lesions with penetration into the dentin, could arrest caries progression clinically and radiographically. In these cases, conventional caries excavation and restorative protocols can be postponed, as long as the sealant is intact. However, the authors emphasized the importance of regular follow-ups of the patient to control sealant failures.

It is important to point out deep caries lesion management based on MID, which represented the highest variation in the participants' answers. Complete removal of carious tissue (no longer recommended) can lead to significantly poor prognosis of pulp vitality. ${ }^{1.5 .13}$ A 10 -year prospective study ${ }^{14}$ concluded that selective removal of carious tissue can promote the arrest of the carious process, the formation of tertiary dentin and mineral gain in the radiolucent area below the restoration. According to the ICCC, 4.5 although the texture of the carious dentin is a subjective criteria, it can serve as a guide when using the selective removal method. The ICCC also referred to stepwise removal. This technique was proposed in the 1960s, and is an option for deep lesions in permanent teeth. ${ }^{15.16}$ The expectation is formation of tertiary dentin, remineralization of demineralized dentin, and reduction in the number of viable bacteria ${ }^{17.18}$. Nevertheless, the second intervention of stepwise excavation in deep lesions increases the risk of pulp exposure and stress. ${ }^{4}$

Clinical cases \#2 and \#3 aimed to assess the management of deep lesions in permanent teeth, based on the ICCC recommendations. In clinical case \#2. most of the participants (37.8\%) proposed stepwise excavation, followed by selective caries removal up to soft $(28.6 \%)$ and hard $(27.8 \%)$ dentin, followed by cavity lining, if there was pulp exposure. These results indicate a great divergence in the responses, but, surprisingly, most of the respondents opted for more conservative approaches (stepwise and caries removal up to soft dentin), an option in line with ICCC recommendations. Even so, a reasonable number of dentists/dental students opted to risk pulp exposure by doing selective caries removal up to hard dentin. Clinical case \#3 presented a radiographic image showing a successful treatment using selective caries removal in a deep carious lesion, with a 10-year follow-up. Clearly, the image shows a line of demineralized dentin underneath the restoration. ${ }^{19}$ In this case, most of the respondents (83\%) acted conservatively by choosing the "any restorative intervention" option; this somehow contradicts their response with respect to clinical case \#2. This behavior may be related to their being informed about the 10-year success rate of the procedure. Another study conducted in southern Brazil found dissimilar results. Most of the professionals chose fewer conservative approaches for deep lesion management, and had different strategies depending on their age (younger dentists chose more conservative approaches than older dentists). However, it is important to emphasize that this study was performed before the ICCC was put into place.

It is unquestionable that even if MID principles are followed, healthy dental tissue will be lost during cavity preparation. Therefore, all attempts should be made to avoid the restorative cycle in an effort to preserve hard tissues and retain teeth in the long term. ${ }^{4.20}$ Nevertheless, the decision to repair, replace or maintain (sealing, polishing) a defective restoration is a challenge, since the criteria 
for replacing a restoration are subjective, and there is no consensus as to what constitutes a deficient restoration. For this reason, clinical case \# 4 was added to the questionnaire, and the results were very surprising, in a positive sense, since most of the participants (68.9\%) stated that they would only polish the dental structure, even if they came across an amalgam restoration. This demonstrates that the replacement of amalgam restorations with no clear indication is currently no longer a priority, at least from the professionals' standpoint.

ICCC sentences 1-4 of the study aimed to evaluate the level of agreement of the participants concerning terminology and management in the field of cariology. Most of the responses ranged between "I totally agree" and "I partially agree." Altogether, these results suggest that the population being surveyed acknowledges the concepts regarding the terminology and management involved in carious tissue removal, and are aware of the theoretical concepts of MID.

This study set out to assess the differences between the responses from participants who studied/study at private and public institutions. It is somewhat surprising that both dentists and students who studied/study at public universities agreed more with the ICCC precepts and were more conservative with respect to their restorative treatment decision-making process than those from private universities. It is important to describe how the Brazilian higher education system works in order to understand the grounding of this finding. Public Brazilian universities are supported by the federal government or by state governments, and do not charge any tuition from students. Usually, high scores are required on the university entrance exam. On the other hand, private schools have high tuition fees, and often have a less competitive selection process. Furthermore, most of the research conducted in Brazil comes from public universities, and may positively impact the education obtained in these institutions. A great number of participants studied/study at the University of Brasilia, the sole public university in the DF. This also explains the difference found in the responses from the groups (private and public), considering that cariology constitutes a decade-long line of research pursued at public universities.

It is important to bear in mind the possible bias in these responses. Studies using questionnaires have a low response rate. We tried offsetting this limitation by sending the questionnaire to a large list of professionals through a radiology company, but the strategy did not prove efficient in the $\mathrm{DF}$, given the poor response rate. This shortcoming made it difficult to obtain answers. Since social media has a better response rate, it may be helpful for researchers to pursue this course in this type of study. Although the sampling was scrutinized, these findings cannot be extrapolated to the entire Brazilian population of dentists and dental students, especially considering that the DF, where the study was conducted, has some peculiarities. This district is divided into 31 administrative areas, one of which is Brasilia, capital of Brazil. This region displays very specific socioeconomic characteristics. Notwithstanding its relatively limited sample, this study offers valuable insights into the impact of dental student MID-related training in public universities.

\section{Conclusion}

In conclusion, regression analysis revealed that the students in the last semester of university are less conservative than dentists, and that the respondents who graduated/were graduating from public dental schools were more aligned with the current concepts of MID and with the ICCC. One of the more significant findings to emerge from this study is that the answers of several participants were not aligned with ICCC recommendations, showing that the management of deep carious lesions still causes restorative therapeutic insecurity.

\section{Acknowledgements}

We thank the deans of the dentistry departments of University of Brasilia. Paulista University (UNIP) (Unieuro). Catholic University of Brasilia (UCB). and Faciplac for contacting the students. We also acknowledge Fenelon for sending the forms to the dental professionals of the Brazilian Federal District. and further extend our appreciation to Capes. 
Are Brazilian dentists and dental students using the ICCC recommendations for caries management?

\section{References}

1. Ricketts DL. Lamon T. Innes NPT. Kidd E. Clarkson JE. Operative caries management in adults and children (Review). Cochrane Database Syst Rev. 2013;(3):CD003808.

2. Schwendicke F. Dörfer CE. Paris S. Incomplete caries removal: a systematic review and meta-analysis. J Dent Res. 2013 Apr;92(4):306-14. https://doi.org/10.1177/0022034513477425

3. Frencken JE. Atraumatic restorative treatment and minimal intervention dentistry. Br Dent J. 2017 Aug;223(3):183-9. https://doi.org/10.1038/sj.bdj.2017.664

4. Schwendicke F. Frencken JE. Biørndal L. Maltz M. Manton DJ. Ricketts D. et al. Managing Carious Lesions: Consensus Recommendations on Carious Tissue Removal. Adv Dent Res. 2016 May;28(2):58-67. https://doi.org/10.1177/0022034516639271

5. Innes NP. Frencken JE. Bjørndal L. Maltz M. Manton DJ. Ricketts D. et al. Managing Carious Lesions: Consensus Recommendations on Terminology. Adv Dent Res. 2016 May;28(2):49-57. https://doi.org/10.1177/0022034516639276

6. Carvalho JC. Qvist V. Aimée NR. Mestrinho HD. Bakhshandeh A. Diagnosis. Risk Assessment. and Treatment Decisions for Occlusal Caries: A Survey from the Danish Public Dental Health Service. Caries Res. 2018;52(1-2):58-70. https://doi.org/10.1159/000484987

7. Weber CM. Alves LS. Maltz M. Treatment decisions for deep carious lesions in the Public Health Service in Southern Brazil. J Public Health Dent. 2011;71(4):265-70. https://doi.org/10.1111/j.1752-7325.2011.00258.x

8. Laske M. Opdam NJ. Bronkhorst EM. Braspenning JC. Sanden WJ. Huysmans MC. et al. Minimally Invasive Intervention for Primary Caries Lesions: Are Dentists Implementing This Concept? Caries Res. 2019;53(2):204-16. https://doi.org/10.1159/000490626

9. Doméjean S. Grosgogeat B. Evidence-based deep carious lesion management: from concept to application in everyday clinical practice. Monogr Oral Sci. 2018;27:137-45. https://doi.org/10.1159/000487840

10. Mertz-Fairhurst EJ. Curtis JW Jr. Ergle JW. Rueggeberg FA. Adair SM. Ultraconservative and cariostatic sealed restorations: results at year 10. J Am Dent Assoc. 1998 Jan;129(1):55-66. https://doi.org/10.14219/jada.archive.1998.0022

11. Alves LS. Giongo FC. Mua B. Martins VB. Barbachan E Silva B. Qvist V. et al. A randomized clinical trial on the sealing of occlusal carious lesions: 3-4-year results. Braz Oral Res. 2017 Jun;31(0):e44. https://doi.org/10.1590/1807-3107bor-2017.vol31.0044

12. Qvist V. Borum MK. Møller KD. Andersen TR. Blanche P. Bakhshandeh A. Sealing occlusal dentin caries in permanent molars: 7-year results of a randomized controlled trial. JDR Clin Trans Res. 2017 Jan;2(1):73-86. https://doi.org/10.1177/2380084416680191

13. Banerjee A. Frencken JE. Schwendicke F. Innes NP. Contemporary operative caries management: consensus recommendations on minimally invasive caries removal. Br Dent J. 2017 Aug;223(3):215-22. https://doi.org/10.1038/sj.bdj.2017.672

14. Maltz M. Henz SL. de Oliveira EF. Jardim JJ. Conventional caries removal and sealed caries in permanent teeth: a microbiological evaluation. J Dent. 2012 Sep;40(9):776-82. https://doi.org/10.1016/i.jdent.2012.05.011

15. Biørndal L. Dentin and pulp reactions to caries and operative treatment: biological variables affecting treatment outcome. Endod Topics. 2002;2(1):10-23. https://doi.org/10.1034/j.1601-1546.2002.20102.x.

16. Biørndal L. Larsen T. Thylstrup A. A clinical and microbiological study of deep carious lesions during stepwise excavation using long treatment intervals. Caries Res. 1997;31(6):411-7. https://doi.org/10.1159/000262431

17. Biørndal L. Stepwise Excavation. Monogr Oral Sci. 2018;27:68-81. https://doi.org/10.1159/000487834

18. Lula EC. Monteiro-Neto V. Alves CM. Ribeiro CC. Microbiological analysis after complete or partial removal of carious dentin in primary teeth: a randomized clinical trial. Caries Res. 2009;43(5):354-8. https://doi.org/10.1159/000231572

19. Alves LS. Fontanella V. Damo AC. Oliveira EF. Maltz M. Qualitative and quantitative radiographic assessment of sealed carious dentin: a 10-year prospective study. Oral Surg Oral Med Oral Pathol Oral Radiol Endod. 2010 Jan;109(1):135-41. https://doi.org/10.1016/i.tripleo.2009.08.021

20. Meyer-Lueckel H. Paris S. When and how to intervene in the caries process. Oper Dent. 2016 Sep;41 S7:S35-47.

https://doi.org/10.2341/15-022-O 


\section{Are Brazilian dentists and dental students using the ICCC recommendations for caries management?. Braz Oral Res. 2020;34:e062. https://doi.org/10.1590/1807-3107bor-2020. vol34.0062}

Table 3

Where is read:

Table 3. ICCC sentences and level of agreement ( 1 - totally disagree, 2 - partially disagree, 3 - do not know, 4 - partially agree, 5 - totally agree).

\begin{tabular}{lcc}
\hline ICCC sentences & $\begin{array}{c}\text { Level of } \\
\text { agreement }\end{array}$ & $\mathrm{n}(\%)$ \\
\hline $\begin{array}{l}\text { "Currently, carious tissue management of permanent } \\
\text { teeth is based on selective removal to avoid pulpal } \\
\text { exposure, and the parameters for removal are the clinical } \\
\text { criteria of hardness and depth. Residual contamination }\end{array}$ & 1 & $84(34.9)$ \\
below the restoration does not compromise the & 3 & $86(35.7)$ \\
restorative treatment." & 4 & $7(2.8)$ \\
\hline & 5 & $27(11.2)$ \\
\hline $\begin{array}{l}\text { "In deep lesions of vital pulp teeth, preservation of } \\
\text { pulp health should be prioritized, thereby allowing soft/ }\end{array}$ & 3 & $104(43.3)$ \\
leathery dentin to be maintained over the pulp." & 2 & $60(25)$ \\
& 4 & $4(1.7)$ \\
\hline $\begin{array}{l}\text { "Selective removal up to firm dentin is the treatment of } \\
\text { choice for both shallow and medium cavitated carious }\end{array}$ & 3 & $21(8.7)$ \\
\hline $\begin{array}{l}\text { lesions." } \\
\text { as complete excavation or complete removal of carious } \\
\text { tissue, is no longer recommended as an approach for }\end{array}$ & 3 & $101(21.3)$ \\
\hline
\end{tabular}




\section{It should read:}

Table 3. ICCC sentences and level of agreement ( 1 - totally disagree, 2 - partially disagree, 3 - do not know, 4 - partially agree, 5 - totally agree).

\begin{tabular}{|c|c|c|}
\hline ICCC sentences & Level of agreement & n (\%) \\
\hline \multirow{5}{*}{$\begin{array}{l}\text { "Currently, carious tissue management of permanent teeth is based on selective removal } \\
\text { to avoid pulpal exposure, and the parameters for removal are the clinical criteria of } \\
\text { hardness and depth. Residual contamination below the restoration does not compromise } \\
\text { the restorative treatment." }\end{array}$} & 5 & $84(34.9)$ \\
\hline & 4 & $86(35.7)$ \\
\hline & 3 & $7(2.8)$ \\
\hline & 2 & $37(15.4)$ \\
\hline & 1 & $27(11.2)$ \\
\hline \multirow{5}{*}{$\begin{array}{l}\text { "In deep lesions of vital pulp teeth, preservation of pulp health should be prioritized, } \\
\text { thereby allowing soft/leathery dentin to be maintained over the pulp." }\end{array}$} & 5 & $104(43.3)$ \\
\hline & 4 & $60(25)$ \\
\hline & 3 & $4(1.7)$ \\
\hline & 2 & $21(8.7)$ \\
\hline & 1 & $51(21.3)$ \\
\hline \multirow{5}{*}{$\begin{array}{l}\text { "Selective removal up to firm dentin is the treatment of choice for both shallow and } \\
\text { medium cavitated carious lesions." }\end{array}$} & 5 & $101(41.9)$ \\
\hline & 4 & $55(22.8)$ \\
\hline & 3 & $6(2.5)$ \\
\hline & 2 & $34(14.1)$ \\
\hline & 1 & 45 (18.7) \\
\hline \multirow{5}{*}{$\begin{array}{l}\text { "Nonselective removal to hard dentin, formerly known as complete excavation or } \\
\text { complete removal of carious tissue, is no longer recommended as an approach for } \\
\text { carious lesion management." }\end{array}$} & 5 & $137(56.8)$ \\
\hline & 4 & $62(25.7)$ \\
\hline & 3 & $14(5.9)$ \\
\hline & 2 & $16(6.6)$ \\
\hline & 1 & $12(5)$ \\
\hline
\end{tabular}

